\title{
O TRÁFICO INTERNACIONAL DE ANIMAIS E A PROTEÇÃO DA DIGNIDADE
}

Florisbal de Souza Del'Olmo

Pós-doutor em Direito pela UFSC (2008), Doutor em Direito pela UFRGS (2004), Mestre em Direito pela UFSC (1999), Especialista em Direito pelo Instituto Superior de Ensino de Santo Ângelo (1996) e Graduado em Direito pela Faculdade de Direito de Santo Ângelo (1987). Especialista em Educação pela Universidade Regional Integrada do Alto Uruguai e das Missões (1986). Graduado em Odontologia pela UFRGS(1966). Atualmente é Professor titular do Programa de Pós-Graduação Stricto Sensu em Direito - Mestrado e Doutorado e da Graduação da Universidade Regional Integrada do Alto Uruguai e das Missões (URI), campus de Santo Ângelo e professor convidado da Universidade Federal do Rio Grande do Sul (UFRGS). Líder do Grupo de Pesquisa CNPq Tutela dos Direitos e sua Efetividade, criado em 2002. Email: florisbaldelolmo@gmail.com

Mário Miguel da Rosa Muraro

Doutorando em Direito no PPGD da Universidade Regional Integrada do Alto Uruguai e Missões (URI), Santo Ângelo Mestre em Direito pela Universidade de Santa Cruz do Sul (UNISC). Especialista em Direito Universidade Federal de Santa Maria (UFSM). Professor do Curso de Direito da Universidade de Caxias do Sul, Campus Universitário de Vacaria, RS. Membro do Grupo de Pesquisa CNPq Tutela dos Direitos e sua Efetividade e participante do Projeto de Pesquisa Direito Internacional do Trabalho e o resgate da dignidade e da cidadania.

\section{RESUMO}

A defesa da biodiversidade e os atributos concernentes à Dignidade adquirem novos contornos com o advento da pós-modernidade. Utilizando como abordagem o métodohipotético-dedutivo ecomoprocedimental o estudo monográfico, buscamos analisar a proteção penal decorrente do crime de tráfico internacional de animais. Através da concepção expansiva do conceito de Dignidade e suaabrangência para espécies não humanas, o estudo realça o aspectoem constituir alteração sensível para a proteção dos direitos fundamentais. A consideração que o direito ao ambiente natural sadio e proteção de todas as espécies é medida de proteção da Dignidade e que estase constitui em um metaprincípio aplicável a todos as espécies vivas do planeta emerge do texto. A alteração da lei de crimes ambientais, sugerindo novos tipos penais para atender tão grave situação é a medida indicada. A inovação influi sobremaneira na nova forma de 
pensar o Direito,não como um sistema estanque, mas sim capaz de atender novas demandas sociais e, entre estas, a proteção de todas as espécies em convivência. O fazer e pensar Direito abriga a adoção de medidas ainda não aplicadas para atender circunstâncias não atendidas.

Palavras-chave: Tráfico Animais; Biodiversidade;Dignidade.

$$
\begin{gathered}
\text { INTERNATIONAL TRAFFIC IN ANIMALS AND } \\
\text { PROTECTION OF DIGNITY }
\end{gathered}
$$

\begin{abstract}
The defense of biodiversity and the attributes concerning Dignity take on new contours with the advent of postmodernity. Using as an approach the hypothetical-deductive method and, as procedural the monographic study, we seek to analyze the criminal protection resulting from the crime of international trafficking in animals. Through the expansive conception of the concept of Dignity and its scope for nonhuman species, the study highlights the aspect in constituting a sensitive change for the protection of fundamental rights. The consideration that the right to a healthy natural environment and protection of all species is a measure of protection of Dignity and that this constitutes a superior legal order applicable to all living species of the planet emerges from the text. The amendment of the law on environmental crimes, suggesting new criminal types to address such a serious situation is the measure indicated. Innovation greatly influences the new way of thinking law, not as a watertight system, but rather capable of meeting new social demands and, among them, the protection of all living species. The do and think Right embraces the adoption of measures not yet applied to meet unmet circumstances
\end{abstract}

Keywords: Animal Trafficking;Biodiversity; Dignity. 


\section{INTRODUÇÃO}

$\mathrm{O}$ presente artigo busca examinar os conceitos relativos à biodiversidade, à Dignidade ${ }^{1}$ humana e não humana, bem como a extensão conceitual da vida digna aos não humanos, no caso em análise, a proteção penal da faunabrasileira em face da constante ocorrência do delito de tráfico internacional de animais. A necessária alteração conceitual sobre Dignidade e suas aplicações aos não humanos constitui em ponto de discussão hodierno, eis que a convivência e proteção da biodiversidade pontuam as discussões sobre proteção do planeta como um ente complexo e portador de vida. A consideração e o reconhecimento do desenvolvimento da consciência ambiental e o apreço da vida como um ente global, abrangendo todas as espécies em busca de convivência harmoniosa, é medida para o enfrentamento da temática objeto.

A Dignidade, constituindo princípio fundamental e referência básica para uma aplicação constitucional democrática, não pode ser dissociada do desenvolvimento da proteção de todas as espécies vivas, possibilitando a realização efetiva dos aspectos constituintes dos conceitos de humanidade e o posicionamento do homem como ente ativo na proteção da biodiversidade, desenvolvimento de uma efetiva cidadania e condizentes com a nova realidade do planeta na proteção das espécies.

A atualidade exige constante repensar de conceitos e definições que não mais atingem seus objetivos iniciais, decorrentes das alterações nas relações interpessoais e nas relações do homem com a natureza que o compõe. $^{2}$

Através de abordagem hipotético-dedutiva,mediante estudo bibliográfico e o enfrentamento de paradigmas operativos na jurisdição brasileira, indica-se uma nova forma analítica da tradicional concepção de cidadania, baseada em uma nova compreensão da extensão do conceito de Dignidade humana.

A análise conceitual sobre biodiversidade e o reconhecimento do homem como ser componente dela, torna-se necessária para fins de compreensão que a Dignidade humana não se concretiza emdistanciamento das demais espécies vivas do planeta, mas sim compõe a complexidade da vida social e deve ser consciente em todas as ações.

\footnotetext{
1 Como referência ao que consideramos relevo do estudo, expressaremos a Dignidade enquanto princípio basilar em destaque com sua inicial em maiúsculo, tanto referente à espécie humana quanto a espécies não humanas, às quais igualmente atribuímos conceitos de Dignidade.

2 Neste sentido, entendemos que o homem é um ser complexo composto por todas as características naturais e no qual os elementos vivos representam suas presenças. A complexidade humana atribui-lhe uma interatividade de sentidos e sensações decorrentes de sua interação com o bioma que o cerca.
} 
Os mecanismos de proteção da fauna, em evolução histórica, constituem fontes de proteção dos animais e dos homens, possibilitando a interação de todas as espécies e o respeito à própria vida humana. $\mathrm{O}$ atual estágio de proteção, especialmente através de tratados internacionais e da lei de crimes ambientais (BRASIL, 1998)caracteriza um grande avanço, mas ainda contempla lacunas a serem observadas para maior eficácia protetiva.

A criminalidade internacional não pode mais ser considerada em face de espaços territoriais nacionais, eis que assim não mais se comporta. Os meios de comunicação e de tráfego de pessoas entre países alteram as concepções pertinentes à criminalidade, especialmente quando abordamos questões pertinentes a crimes internacionais.A análise do tráfico internacional de animais, sua distinção para o delito de exportação irregular e a inexistência de conduta típica são objetos referentes do estudo.

Antes de encaminharmos para as considerações finais, buscaremos identificar a atipicidade de condutas classificadas como exportação de animais prevista na Lei de Crimes Ambientais, com consequente inexistência de imputação penal efetiva, identificando a necessidade de alteração do tipo penal correspondente.

Analisar a atual compreensão sobre a biodiversidade, os conceitos e aplicações do princípio da Dignidade e o tráfico internacional de animais, em uma reflexão que busca identificar a circularidade da vida no planeta, é o objeto deste estudo. Anecessária alteração do paradigma relativo ao respeito e proteção da Dignidade a todos os seres vivos e a aplicação dimensional do Direito penal como mecanismo de proteção de direitos transindividuais em um sistema social complexo do qual o Direito não pode se furtar ao exame. Não se trata de um estudo final, mas, conforme procedimento, um exame sobre as atuais disposições jurídicas e indicações para alterar padrões préconceituais muitas vezes não clarificados tecnicamente.

\section{A BIODIVERSIDADE COMO COMPONENTE DA DIGNIDADE DOS SERES VIVOS}

As alterações decorrentes da pós-modernidade ${ }^{3}$ exigem severaobservação quanto às novas formas dereconhecimento $\mathrm{e}$ relacionamento entre o homem e os demais seres vivos do planeta. Não

\footnotetext{
3 Neste aspecto, a discussão teórica sobre a efetiva presença da pós-modernidade no Brasil ou a presença de uma modernidade tardia, rediscutindo a identificação na consideração de que o conceito e significantes da modernidade não se concretizaram in totum em nosso país.
} 
se constitui mais a Terra um planeta dissociado de sua biodiversidade e a sobrevivência humana encontra-se cada vez mais codependente da sobrevivência das demais espécies. Analisar este aspecto da vida é relevante para a compreensão da temática central, em especiala construção de novos paradigmas em relação às espécies não humanas.

\subsection{Biodiversidade: aspectos conceituais na modernidade}

As mudanças decorrentes da conceituação e da neocompreensão ${ }^{4}$ sobre a diversidade da vida planetária geram o que Morin eKern (1993, p. 78) identificam como um "processo multiforme de degradação da psicoesfera, ou seja, de nossas vidas mentais, afetivas e morais"constituindo tal situação como produtora de consequências circulares em cadeia, uma circularidade irreflexiva e capaz de embotar a compreensão sobre as relevâncias psicossociais.

Consoante manifestação deCervi e Cervi (2016, p. 75), a necessária alteração paradigmática se impõe no atual estágio social. " [...] Nesses rumos, surgiu a proposta de transição do paradigma mecanicista ou cartesiano para o paradigma ecológico, constituindo-se em um processo que está ocorrendo de diferentes formas e velocidades nas várias áreas científicas".

Para que ocorra a transição, emerge o espectro ${ }^{5}$ da educação como mecanismo de proporcionar condições de compreensão e evolução semântica. Neste aspecto, a pós-modernidade traz consigo o novo entendimento do homem enquanto componente de um sistema vivo, ou seja, não mais centrado na característica antropocêntrica, mas sim em uma característica sistêmica onde o homem insere-se em uma rede de vida e interação, ou, no dizer de Cervi e Cervi (2016, p.75) "[...] A substituição de valores tem sido reconhecida por uma forma ecológica ou holística de perceber a realidade" significando a alteração de paradigma existencial, emergindo o paradigma ecológico como ponto referencial diferenciador.

Conceituar biodiversidade é recorrer aos clássicos conceitos de meio ambiente e sua necessária readequação às modernas percepções sobre a temática 'existência viva' no planeta. A denominação é decorrente da

\footnotetext{
4 Referimos como neo-compreensão em decorrência das significativas alterações sociais em relação ao reconhecimento das demais espécies e a sustentabilidade imprescindível para a sobrevivência das espécies no planeta.

5 Referenciamos espectro para fins de identificar a sempre presente, mas não compreendida na integralidade, necessidade de educação para igualdade.
} 
evolução dos conceitos segmentados abordados até então de forma muitas vezes segregadas, relativos à ecologia, biologia e biogeografia.

Nesse aspecto, o conceito decorrente da Convenção sobre a Diversidade Biológica adotado por Milaré (2007, p.113)entende que a "diversidade biológica significa a variabilidade de organismos vivos de todas as origens e os complexos ecológicos de que fazem parte, compreendendo ainda a diversidade dentro das espécies, entre espécies e ecossistemas".

A proteção da biodiversidade e suas decorrências encontra eco em discussões nas mais variadas áreas da ciência e que, na concepção mais ampla, impõe ao Estado o dever de proteção da mesma. Nesse aspecto, a manifestação de Canotilho (2008, p. 181) explicita que "A ideia de proteção especificamente referenciada ao ambiente significa, desde logo, que o Estado tem o dever". A compreensão sobre a potestade poderdever é o que indiretamente abordamos no item que segue.

\subsection{A proteção da biodiversidade e a sobrevivência do planeta}

A compreensão conceitual e operativa da biodiversidade torna relevância ao observarmos que as diversas espécies que compõem a biosfera correlacionam-se, gerando uma interdependência substancial para fins de estabilidade do planeta. Nesse aspecto, Milaré especifica a relevância da terminologia ao declarar que 'biodiversidade sugere uma vinculação mais profunda, direta e essencial dos indivíduos e das espécies com a teia da vida em que estão inseridos, traduzindo melhor a unidade na pluralidade e a pluralidade na unidade" (MILARÉ, 2007, p.548).

Busca-se na adoção de novas denominações não somente o inovar em nomes, mas sim de qualificar a abordagem e realçar o aspecto atinente à compreensão sistêmica do conjunto vivo da biosfera, ou seja, a vida é o complexo de relações entre todos os seres vivos, interdependentes e coparticipes na proteção e desenvolvimento global, tal como refere a constante busca da sustentabilidade referenciada nos objetivos do desenvolvimento sustentável do milênio pelas Nações Unidas (ONU, 2015).

$\mathrm{O}$ relevo do respeito e proteção à biodiversidade decorrente de uma necessidade básica de sobrevivência da própria espécie humana, que, no decorrer dos tempos, despega-se de um antropocentrismo egoístico e começa a compreender a vida em conjunto com os demais seres na Terra. Nessa leitura, a manifestação de Leite e BelloFilho (2004, p. 206-208) 
identificam a alteração de paradigma ao afirmar que "a modernidade é a inauguração de um grande projeto para o homem, responsável pela sua vida, pelo destino da humanidade". Na sequência da construção, os mesmos autores identificam a necessidade decorrente de tal projeto, ao pontuar "e que traz uma cidadania ecológica, que se caracteriza, fundamentalmente, na relação harmônica entre homens, animais e plantas".

A complexidade decorrente da pós-modernidade traz consigo uma rede de questionamentos sobre o significado da existência humana e a necessária superação da visão do homem enquanto centro, passando a uma visão relacional e sistêmica dos seres vivos componentes do planeta. Uma tomada de consciência sobre os perigos decorrentes de uma cultura extrativista e destruidora do planeta, identificado por Morin ao expressar sobre os problemas globais que afetam o planeta e as grandes catástrofes geradas pela exploração humana, "desde então, a consciência ecológica se converteu em uma tomada de consciência sobre o problema global e o perigo que ameaça ao planeta. Como afirma Pelt citado por Morin e Kern (1993,p.80), 'O homem destrói, um a um, os sistemas de defesa do organismo planetário". ${ }^{6}$

Estudar a biodiversidade pressupõe, de forma indireta para alguns, mas imprescindível para todos, observar as necessidades intrínsecas a todos os seres vivos, entre os quais a espécie humana, em preservar condições dignas de coexistência e desenvolvimento, sob pena do perecimento das espécies terrenas mais débeis e, a nosso ver, salvo eventuais exceções, não está a espécie humana entre as mais capazes de sobrevivência a um colapso planetário.

\section{O PRINCÍPIO DA DIGNIDADE E A DIGNIDADE NÃO HUMANA}

O conceito de dignidade e sua definição foram sendo construídos no decorrer da história e chegam ao século XXI repletos de significado em si, como um valor supremo, construído pela razão jurídica (NUNES, 2002, p.46).

A conceituação específica da Dignidade é situação complexa, exprimindo escritos sobre a "qualidade de o ser humano ser humano, uma manifestação aberta e de interpretação variada.Nesse sentido, emerge 6 Tradução livre pelos autores de "desde entonces, laconsciencia ecológica se ha convertido enla toma de conciencia del problema global y del peligro global que amenazam al planeta". Como afirma JeanMarie Pelt 'El hombredestruye, uno a uno, los sistemas de defensa del organismo planetario"”. 
a compreensão de que a Dignidade não é um conceito apropriável, mas sim um conjunto de qualidades e demonstração de respeito à humanidade, efetuando releitura da terminologia latina "dignitate", que significa honradez, virtude e consideração, transmutando-a para aplicação ampla de toda a "consideração que deve merecer e que não pode ser dissociada do ser humano e suas relações sociais e ambientais. ${ }^{7}$

\subsection{A Dignidade dos seres humanos e sua extensão}

Nessa ampla acepção, garantir a Dignidade é garantir a própria existência humana, "o" princípio a ser respeitado e imposto frente a maiorias ou ações estatais, possibilidade com que as alterações relacionais possam receber o devido resguardo e adaptações constantes do evolutivo quadro de relacionamento do homem enquanto ser social e mútuo dependente de seus ambientes de atuação, natural ou artificial.

Em outro sentido referencial, ao abordarmos a Dignidade como atributo igualmente atribuível a espécies não humanas, passamos a considerar a relevante alteração do comportamento social em relação ao trato dos demais seres vivos do planeta.Neste estudo, em especial,os animais e sua proteção observada no território nacional, de forma mais específica pela lei de crimes ambientais (BRASIL, 1998). A proteção animal é objeto de inúmeras manifestações legislativas recepcionadas e originadas internamente, com o reconhecimento necessário de serem os mesmos objetos de proteção estatal.

A Dignidade animal não se manifesta em termos expressos, ousando manifestar um conceito diferenciado para a mesma, mas o ato de o não humano ser "digno"e de direitos e, analogicamente,poder ser atribuído a ele, em reconhecimento e consideração social,bem como mecanismos de proteção, referenciando não somente os animais domésticos, mas, de igual forma, os animais não domesticáveis, silvestres e exóticos.

Os seres não humanos passaram gozar de apreço e proteção diante da necessária e imprescindível proteção ao equilíbrio e desenvolvimento sustentável do homem e dos ambientes naturais do planeta. ${ }^{8}$ A consciência

7 Neste aspecto, recomendamos a leitura de SARLET, Ingo Wolfgang (org.). MAURER, Béatrice et al.Dimensões da Dignidade - Ensaios de Filosofia do direito e Direito Constitucional. 2. ed. 2.tir. Porto Alegre: Livraria do Advogado Editora, 2013.

8 Em sentido análogo, publicamos estudo peculiar sobre o habeas corpus concedido ao chimpanzé Cecilia, sobre o título A proteção da dignidade da pessoa não humana: o habeas corpus do caso Cecilia.Disponível em: $<\mathrm{http}: / /$ revista.unicuritiba.edu.br/index.php/RevJur/arti$\mathrm{cle} / \mathrm{view} / 2009>$. Acesso em 13.10.2017. 
sobre a biodiversidade e sua necessária estabilidade para salvaguardar a existência terrena torna a consciência ecológica uma imposição de sobrevivência.

A Declaração Universal dos Direitos dos Animais (ONU, UNESCO, 1997) enaltece "que o reconhecimento pela espécie humana do direito à existência das outras espécies animais constitui o fundamento da coexistência das outras espécies no mundo" e ainda, a consideração que o "respeito dos homens pelos animais está ligado ao respeito dos homens pelo seu semelhante".

Tais dispositivos, em nossa compreensãonão constituemmanifestação meramente expositiva, mas,consideradas as circunstâncias de aplicabilidade, as emanações do Direito internacional são vinculativas à Dignidade da própria espécie humana. A indeterminação sobre a legitimidade de proteção aos seres não humanos passa a ter conotação distinta, reconhecendo aos mesmos direitos até então não discutidos e impondo limites de sua inadequada fruição pelos homens. ${ }^{9}$

Ao especificar limitações e ações protetivas, a Declaração, de forma indireta ou até mesmo intrínseca, constitui o conceito de Dignidade aos animais, impondo ao homem não somente o respeito aos seres de sua espécie, mas de igual forma o trato e a responsabilidade para com os seres não humanos. Compreendemos em decorrência de tal situação, a existência de um atributo superior de Dignidade - uma Dignidade máster, supralegal, decorrente de valores de vida atinentes às espécies planetárias e não somente aos homens -, abrangendo valores coletivos a todos os seres vivos que, em momento posterior, passa a ser apreendida pelas subespécies de vida na terra, decorrendo deste aspecto a manifestação adrede que a Dignidade também é atributo dos seres não humanos.

\subsection{O reconhecimento da Dignidade aos seres não humanos}

A Dignidade animal emerge, pois, da consideração evolutiva dos atributos humanos e o reconhecimento que determinados valores devem ser deslocados para um patamar avaliativo superior aos corriqueiros, ou seja, o desenvolvimento do estudo sobre as dimensões dos direitos fundamentais. Aproveitando manifestação de Peter Singer, quando expressa que "[...] se

9 ARTIGO 2: a) Cada animal tem direito ao respeito. b) O homem, enquanto espécie animal, não pode atribuir-se o direito de exterminar os outros animais, ou explorá-los, violando esse direito. Ele tem o dever de colocar a sua consciência a serviço dos outros animais. c) Cada animal tem direito à consideração, à cura e à proteção do homem. 
um ser sofre, não há justificativa moral para recursar levar em consideração esse sofrimento. Não importa a natureza do ser, o princípio da igualdade exige que seu sofrimento receba a mesma atenção que sofrimentos semelhantes de qualquer outro ser [...]" (SINGER, 1975). Observamos a imposição da proteção ao meio ambiente e a impossibilidade de apropriação individual sobre o patrimônio comum da humanidade, ressaltando serem direitos transindividuais, coletivos, destinados à proteção da espécie humana através da proteção de todas as espécies de convivência, fauna e flora.

Na leitura interrogativa de Singer (2017, p. 62-100), questionando sobre as manifestações éticas e sua complexidade, ao analisar capítulo sobre a relação ética para com os animais, esse autor exemplifica uma série de situações onde o reconhecimento da Dignidade se torna referencial para condutas. Nesse aspecto, inicia sua construção especificando o caso dos ovos das galinhas criadas em gaiolas minúsculas, onde a comoção gerada pelas péssimas condições de criação de galinhas em gaiolas extremamente apertadas e sem condições motivaram à decisão de Comissão Europeia proibindo tal prática. $\mathrm{Na}$ continuidade, aborda situações éticas no trato com outras espécies animais, tais como as baleias e sua caça, o consumo de carnes bovina e suína e as possibilidades cientificas em desenvolvimento com a criação da carne in vitro e ainda, em consonância com nosso artigo adrede referenciado, sobre a situação de habeas corpus a um chimpanzé nos Estados Unidos da América.

Especificamente sobre essa última situação, ao discorrer sobre a consideração de um chimpanzé ser 'pessoa', manifesta que "declarar que um chimpanzé é uma pessoa não significa dar-lhe direito a voto, ir à escola ou levar alguém ao tribunal por difamação. Significa apenas dar-lhe o direito mais básico e fundamental de ter estatuto jurídico em vez de ser considerado um objeto"(SINGER, 2017, p. 91-93).

Ao abordar sobre o aspecto ético o trato dos animais, deflui da mesma o reconhecimento da Dignidade, eis que as inúmeras situações enfrentadas, o sentimento de consideração e respeito, a afetuosidade desenvolvida e uma série de outras alterações inter-relacionais do homem com os demais seres vivos, trazem consigo a nova significação da Ética e Dignidade, uma evolução necessária para nossa compreensão enquanto seres dotados de inteligência, emoção e consciência plena de nossa existência cósmica.

Obviamente que a temática ainda se encontraem gênese, a ser 
desenvolvida e maturada mediante a análise dos relacionamentos humanos em relação aos demais seres do planeta. Contudo, esta breve reflexãonão pode deixar de ser considerada, pois, ao abordar a Dignidade como mecanismo de respeito e proteção, a quebra do paradigma estabelecido faz-se necessária para pensar o novo como o direito de discutir o direito, conforme manifesta Lefort (1991), ao discorrer sobre o regime democrático. Não podem existir matérias indiscutíveis ou inalteradas no âmbito da aplicação judicial, sob pena de transmutarmos nossa incipiente democracia em regimes autoritários sob o jugo de maiorias estabelecidas.

A capacidade de (re)pensar o já pensado é o objetivo da ciência jurídica; o emergir de novos reconhecimentos em relação aos direitos fundamentais do homem e seus relacionamentos com outras espécies. A consideração pertinente a características de Dignidade a pessoas não humanas busca a concretização de que, embora muitos caracterizados como servientes e utilitários à própria sobrevivência do homem, não podem ser tratados meramente como objeto/propriedade, eis que dotados de inteligência, sensações de dor e de apreço constatados e, ainda, compondo a própria Dignidade fundamental decorrente do reconhecimento e necessidade de afeto correlacional do homem, ser vivo este cada vez mais solitário dentro da multidão e seus companheiros 'animais' na senda da vida terrena.

O reconhecimento de que as espécies não humanas gozam de proteção para com sua Dignidade, impondo restrições de caráter legal aos seus eventuais detentores, - reiteramos a inapropriação do entendimento de propriedade -, coagindo-os ao trato digno em decorrência do próprio cerceamento de liberdade a que estão submetidas por força da atuação humana é uma das características da pós-modernidade.

A Dignidade humana abrange e é abrangida pela proteção da biodiversidade, referenciando o desenvolvimento inter-relacional entre as espécies habitantes de Gaia. A proteção das demais espécies não se revela somente uma medida de beneplácito,mas decorre de uma verdadeira necessidade frenteà complexidadedo equilíbrio do planeta e o desenvolvimento pleno da própria espécie humana. A Dignidade de todas as espécies, entre as quais a humana, compõe parcela do todo, é a referência gênese para tal compreensão e, embora se discuta a conceituação e amplitude do termoDignidade, ousamos entendê-la dentro de valores meta-humanos que transmutam o inconsciente coletivo, refletindo nos valores subjetivos a consideração e respeito necessários a todas as espécies 
em vida, protegendo a biodiversidade como componente de um todo vivo, o planeta Terra e seus habitantes.

\section{A PROTEÇÃO DA FAUNA MEDIANTE A LEGISLAÇÃO PENAL: O CRIME DE TRÁFICO DE ANIMAIS}

Ao analisar no presente item a questão pertinente ao tráfico de animais, passamos a referenciar a real dimensão de tal objeto. A insensatez e ganância humana, ao escravizar e coisificar todas as demais espécies, faz do tráfico de animais a $3^{\mathrm{a}}$ maior atividade ilícita no mundo, girando valores entre 10 e 20 bilhões de dólares norte-americanos. Desses, o Brasil concorre com percentuais variáveis entre $5 \%$ e $15 \%$, ou seja, valores extremos que decorrem de crimes constantes contra a fauna nacional (RENCTAS, 2004).

Sobre a relevância da matéria para a sociedade, deve-se considerar que as espécies não evoluíram de forma independente, mas que possuem suas relações intra e interespecíficas e com o meio físico-químico. Essas relações, muitas vezes não compreendidas ou desconhecidas, contribuem para a complexidade, funcionamento e equilíbrio dinâmico dos ecossistemas - biodiversidade e biosfera. Ao se eliminar espécies, muitas dessas interações se perdem, sendo difícil prever quais as reações e consequências nos ecossistemas (RENCTAS, 2004).

Corroborando com tal identificação valorativa do tráfico de animais no Brasil, o Relatório da Comissão Parlamentar de Inquérito (CPI) destinada a "investigar o tráfico ilegal de animais e plantas silvestres da fauna e da flora brasileiras" - CPITRAFI (BRASIL, CÂMARA DOS DEPUTADOS, 2004) igualmente referencia ser o tráfico de animais a $3^{\text {a10 }}$ maior atividade ilícita no mundo, sendo superado somente pelo tráfico de armas e o tráfico de drogas.

A questão assume contornos extremamente significativos, não exclusivamente pelo aspecto atinente aos valores envolvidos, mas também em face da proteção dos biomas e diversidades vivas do país. Segundo os relatórios referenciados, o tráfico se distingue em três grandes segmentos: tráficos para colecionadores e zoológicos; tráfico de animais para fins

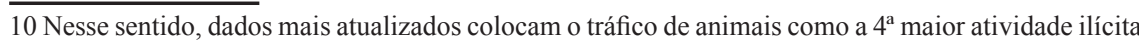
do mundo, elencando no rol o tráfico de armas, de drogas, de pessoas e o de animais. Matéria da Agência Brasil - Últimas notícias do Brasil e do mundo:Tráfico de animais selvagens é o quarto negócio ilegal mais lucrativo do mundo, publicada em • 23/11/2016 06h00.Disponível em: $<$ http://agenciabrasil.ebc.com.br/internacional/noticia/2016-11/trafico-de-animais-selvagens-e-o-quarto-negocio-ilegalmais-lucrativo >. Acesso em: 13.10.2017 
científicos, classificado como biopirataria; e o tráfico de animais para pet shops. Buscaremos neste item examinar os mecanismos de enfrentamento na esfera penal e ao que consideramos como insignificância protetiva face à dimensão do crime abordado.

\subsection{Os números e a relevância social: a biodiversidade clama por socorro e proteção efetiva}

Conforme manifestamos adrede, a dimensão atribuída ao tráfico de animais somente é superada pelo tráfico de armas e de drogas, ou seja, por dois flagelos reconhecidos internacionalmente, discutidos e comentados em todas as esferas sociais mas, e sempre o mas presente, a $3^{\text {a }}$ maior incidência criminal do planeta, o tráfico de animais, não recebe a mesma consideração e cuidado, constituindo-se em um velamento de interesses e justificativas que não abordam ou atacam de forma direta a criminalidade envolvida.

Segundo artigo produzido pela Aliança Internacional do Animal (AILA), $\mathrm{ONG}^{11}$ que possui como objetivo a proteção dos animais domésticos, domesticáveis, silvestres e selvagens, a participação brasileira no mercado negro internacional de animais assume proporções extremadas, no relatório, "Em termos nacionais, podemos dizer que o BRASIL participa de tal atividade criminosa com cerca de $15 \%$ na participação do comércio internacional, promovendo uma movimentação aproximada de US\$1,5 bi com o tráfico internacional de animais" (AILA, 2017).

No mesmo escrito, ao demonstrar a relevância sobre os números internacionais do tráfico ilícito de animais, especifica questões relativas ao tráfico interno, manifestando que “... Não bastasse a atividade internacional, o desrespeito à vida animal se desenvolve internamente no país, sendo constatado que $30 \%$ dos animais silvestres são exportados, enquanto que os $70 \%$ restantes envolvidos na atividade são comercializados internamente".

Os aspectos históricos protetivos podem ser considerados mais efetivos a partir da Convenção sobre o Comércio Internacional da Flora e Fauna Selvagens em Perigo de Extinção-CITES (BRASIL, 1975), no qual o Brasil foi signatário. A Convenção Internacional em apreço buscou regulamentar o comércio internacional de animais, dispondo sobre as legalidades pertinentes e, por exclusão, indicando as atividades típicas de 11 Organização Não Governamental 
ilícitos, especialmente a questão do tráfico internacional. ${ }^{12}$

O objetivo principal da Convenção é a regulamentação do comércio e o controle das ameaças atinentes às espécies em comercialização, impondo inclusive procedimentos às partes envolvidas a fim de elucidar questões atinentes a eventuais perecimentos ou desacordos com as regras estatuídas, ou seja, estabelecendo o diálogo transnacional como forma de controle das atividades comerciais regulares e, in excluendo, do comércio ilícito.

A Convenção estabelece ainda a classificação das espécies em três categorias ou níveis conforme os Anexos: Anexo I identificando todas as espéciesameaçadas de extinção que são ou possam ser afetadas pelo comércio; o Anexo II, todas as espécies que, embora não se encontrem necessariamente em perigo de extinção, poderão chegar a essa situação, e outras espécies que devam ser objeto de regulamentação, a fim de permitir um controle eficaz do comércio; por fim, no Anexo III, incluirá todas as espécies que qualquer das partes declare sujeitas, nos limites de sua competência, a regulamentação para impedir ou restringir sua exploração e que necessitam da cooperação das outras partes para o controle do comércio.

Com a finalidade de suporte e apoio ao cumprimento da Convenção e tratados pertinentes à matéria, a Organização das Nações Unidas (ONU) criou em1972 o escritório de apoio dentro do Programa das Nações Unidas para o Meio Ambiente (PNUMA), que possui uma atuação de caráter educativo e facilitador ${ }^{13}$ das relações internacionais.

Retornando aos números abrangidos, ao abordar questões pertinentes ao 'desenvolvimento sustentável' em Agenda 21, Leonardo Boff relata que a lógica interna do mercado implica em uma extenuação dos recursos naturais e a extinção de cerca de 3000 espécies ao ano quando o normal seria de 300. Ao expor sobre esta situação reestabelece conceito para definir a relevância da sustentabilidade, afirmando que "A sustentabilidade significa que no processo evolucionário e na dinâmica da natureza vigoram interdependências, redes de relações inclusivas, mutualidades e lógicas de cooperação que permitem que todos os seres convivam, coevoluam e se

12 CITES; op. cit.: ARTIGO II - Princípios Fundamentais. 1. O anexo I incluirá todas as espéciesameaçadas de extinção que são ou possam ser afetadas pelo comércio. O comércio de espécimes dessas espécies deverá estar submetido a uma regulamentação particularmente rigorosa a fim de que não seja ameaçada ainda mais a sua sobrevivência, e será autorizado somente em circunstâncias excepcionais.

13 Para maiores informações, consultar em: <https://nacoesunidas.org/agencia/onumeioambiente>. Acesso em 30.09.2017. 
ajudem mutuamente para se manterem vivos e garantir a biodiversidade" (BOFF, 2006).

Nesta singela análise, podem ser observadas diversas ponderações atinentes à proteção da biodiversidade nacional, especialmente a fauna no presente estudo, representando uma das maiores atividades ilícitas do planeta e com repercussão criminal não imaginável pela maioria absoluta da população. Urge a adoção de medidas mais efetivas para a proteção ou intimidação dos agentes criminosos, buscando atingir uma redução da incidência deste tipo delitivo e, não somente nesse aspecto, proteger a Dignidade e demais atributos pertinentes à qualidade de seres vivos das espécies da fauna nacional.

\subsection{Do crime de tráfico de animais e sua pífia tipificação penal}

A abordagem neste item dar-se-á em dois momentos distintos. Em um primeiro aspecto a análise das atuais disposições penais protetivas da fauna, sua conceituação e características e penalidades. Em um segundo instante, passando da constatação anterior, nossa compreensão sobre a fragilidade tipificadora e a necessidade de criação de novos tipos penais mais específicos, buscando a aplicação de uma 'lex specialis' em detrimento da disposição genérica do artigo 29 da Lei de Crimes Ambientais.

O Direito penal, ao longo de sua história, sinteticamente retratada neste, possui objetos de proteção que vão compondo as necessidades geradas pelo sistema social, mesmo que não organizado e estratificado como tal para fins científicos.

O 'dimensionamento' que manifestamos em outros estudos reflete a circularidade e evolução das demandas sociais. Não se trata de uma classificação hermética e geracional, ou seja, que venha a surgir por condições determinadas em momentos históricos determinados. A compreensão dimensional decorrente de ondas de aplicação que se expandem ou retraem conforme as instabilidades comportamentais se manifestam no contexto social.São construções interdependentes e interrelacionadas, onde não há supremacia de uma em detrimentos de outras, mas comunicações permanentes e autorreferentes. As dimensões não manifestam, para fins de estudo, tão somente aspectos objetivos e subjetivos, mas as empregamos como amplitudes aplicativas para a matéria penal.

Nesse aspecto, no que denominamos de Quarta Dimensão ${ }^{14}$, em

14 Sobre as "Dimensões do Direito Penal", termo cunhado pelos autores para identificar a evolução 
uma situação oriunda da explosão econômica e extrativa, a necessidade de conservação de bens comuns aos povos, especialmente de caráter ambiental e expropriativos, uma proteção penal estabelecendo limites e atuando de forma proativa na defesa de ambientes naturais - espécies e espaços naturais-, em grave risco de extinção pela ação humana desenfreada. Novas formas punitivas com o fim de estabelecer limites à ação humana na fruição e destruição dos bens naturais e a preservação da própria espécie humana enquanto componente de um sistema natural.

O tipo penal hoje utilizado refere ao ato de exportar animal da fauna silvestre, nativa ou em rota migratória. A pena atribuída a tal conduta é de 6 (seis) meses a 01 (um) ano e multa, significando um apenamento de menor relevância e sujeito à aplicação primária de medidas alternativas à pena privativa de liberdade. $\mathrm{O}$ núcleo da conduta reveste-se no verbo exportar e deflui dessa conduta nuclear nosso primeiro questionamento sobre o tipo penal. ${ }^{15}$

Exportar, identificação de prática comercial, em interpretação gramatical indica a"ação de remeter, expedir ou enviar para outra nação; vender para o estrangeiro, para fora do país". ${ }^{16}$ Nessa seara, considerando as peculiaridades da matéria objeto, temos a possível de duas formas de conduta para com o núcleo exportar. Em uma das formas o ato da simples remessa das espécies protegidas sem o intuito de lucro e, outra delas, a finalidade de comércio, ou seja, o enriquecimento mediante a venda de animais da fauna brasileira para o exterior.

Diante dessas possibilidades de condutas, emerge nossa irresignação para com a atual tipificação referencial do crime de tráfico internacional de animais.Observa-se ainda, na análise da legislação protetiva citada, que a remessa de peles e couros para o exterior possui

da proteção penal ao longo da história, ler em DEL'OLMO, Florisbal de Souza e MURARO, Mário Miguel da Rosa:Aproteção da dignidade da pessoa não humana: o habeas corpus do caso Cecilia, disponível em: Revista Jurídica UniCuritiba, vol. 01, n. 46, Curitiba, 2017. pp. 281 - 299, DOI: 10.6084/m9.figshare.5172403.Disponível em: <http://revista.unicuritiba.edu.br/index.php/RevJur/article/view/2009/1290>. Acesso em 13.10.2017

15 BRASIL. Lei 9.605/98. Lei de Crimes Ambientais. Art. 29. Matar, perseguir, caçar, apanhar, utilizar espécimes da fauna silvestre, nativos ou em rota migratória, sem a devida permissão, licença ou autorização da autoridade competente, ou em desacordo com a obtida:Pena - detenção de seis meses a um ano, e multa.§ $1^{\circ}$ Incorre nas mesmas penas: I - ...II-apenamento...III - quem vende, expõe à venda, exporta ou adquire, guarda, tem em cativeiro ou depósito, utiliza ou transporta ovos, larvas ou espécimes da fauna silvestre, nativa ou em rota migratória, bem como produtos e objetos dela oriundos, provenientes de criadouros não autorizados ou sem a devida permissão, licença ou autorização da autoridade competente.

16 LÉXICO. Dicionário de português online. Disponível em: $<$ https://www.lexico.pt/exporta $>$.Acesso em20.09.2017. 
apenamento em triplo ${ }^{17}$ do disposto no artigo 29 citado.

A finalidade da criação do tipo penal especial ou incriminador é, dentro de uma característica da dogmática penal, impor a condução de um 'dever ser' social, através de mecanismos de prevenção geral impondo 'medo' da punibilidade em face do cometimento de crimes tipificados.

A pena atribuível ao crime de tráfico internacional de animais mediante o núcleo 'exportar' possui uma insignificância punitiva extrema, punindo com menor intensidade que o delito de furto simples, por exemplo, não sendo capaz de causar qualquer tipo de constrangimento ou consideração no momento da prática criminosa, eis que, de conhecimento público notório, tais condutas gerarão ao infrator responsabilizações de menor potencial ofensivo e incapazes de incutir um comportamento diverso.

Na busca de uma maior efetividade aos mecanismos punitivos, procurando cumprir as necessidades de prevenção, geral e especial, ousamos indicar alterações na redação dos tipos penais incriminadores para o tráfico de animais. Adotando por referência os tipos pertinentes às práticas comerciais ilícitas internacionais, a redação dos crimes de contrabando e descaminho representa um indicativo mais apropriado de conduta típica, bem como possibilita o quantificar das penas de forma mais apropriada a essa forma de prática, geralmente por meio do crime organizado e de dificílimo controle e repressão pelo Estado.

Nesse sentido, conscientes de que sempre existirão críticas à ousadia, disporíamos novos tipos penais na Lei 9.605/98 nas seguintes composições:

\section{Artigo 29-A - Descaminho de Animais}

Art. 334. Iludir, no todo ou em parte, o pagamento de direito ou imposto devido pela entrada no país ou pela saída para o exterior,de espécies da fauna silvestre, nativa ou em rota migratória ou sem o cumprimento das disposições legais. Pena - reclusão, de 1 (um) a 4 (quatro) anos. $1^{\circ}$ Incorre na mesma pena quem: I -adquire, vende, expõe à venda, mantém em depósito ou, de qualquer forma, utiliza em proveito próprio ou alheio, no exercício de atividade comercial ou industrial, animais de espécies descritas no caput, de procedência estrangeira que introduziu clandestinamente no

17 BRASIL. Lei 9605/98 Art. 30. Exportar para o exterior peles e couros de anfíbios e répteis em bruto, sem a autorização da autoridade ambiental competente: Pena - reclusão, de um a três anos, e multa. 
País ou importou fraudulentamente ou que sabe ser produto de introdução clandestina no território nacional ou de importação fraudulenta por parte de outrem; II- adquire, recebe ou oculta, em proveito próprio ou alheio, no exercício de atividade comercial ou industrial, animais de espécies descritas no caput do artigo, de procedência estrangeira, desacompanhada de documentação legal ou acompanhada de documentos que sabe serem falsos. $\S 2^{\circ}$ Equipara-se às atividades comerciais, para os efeitos deste artigo, qualquer forma de comércio irregular ou clandestino de animais das espécies citadas, para fins de entrada ou saída para o estrangeiro, inclusive o exercido em residências. $\S 3^{\circ} \mathrm{A}$ pena aplica-se em dobro se o crime de descaminho é praticado em transporte aéreo, marítimo ou fluvial.

\section{Artigo 29-B - Contrabando de Animais}

Art. 334-A. Importar ou exportar espécies da fauna silvestre, nativa ou em rota migratória proibidos e comercialização:Pena - reclusão, de 2 (dois) a 5 ( cinco) anos§ $1^{\circ}$ Incorre na mesma pena quem: I - importa ou exporta clandestinamente animais das espécies citadas no caput, que dependa de registro, análise ou autorização de órgão público competente;II - vende, expõe à venda, mantém em depósito ou, de qualquer forma, utiliza em proveito próprio ou alheio, no exercício de atividade comercial ou industrial, animais proibidos pela lei brasileira; III- adquire, recebe ou oculta, em proveito próprio ou alheio, no exercício de atividade comercial ou industrial, animais proibidos pela lei brasileira. $\S 2^{\circ}$ - Equipara-se às atividades comerciais, para os efeitos deste artigo, qualquer forma de comércio irregular ou clandestino de animais das espécies citadas, para fins de entrada ou saída para o estrangeiro, inclusive o exercido em residências. $\S 3$-A pena aplica-se em dobro se o crime de contrabando é praticado em transporte aéreo, marítimo ou fluvial.

Inobstante o aspecto da ousadia, entendemos que novas figuras incriminadorasproporcionarão maior eficácia na proteção da biodiversidade nacional. A busca de figuras típicas mais efetivas traz consigo a possibilidade de potencializar a atuação preventiva da matéria penal, não se constituindo, no caso presente, mera inflação legislativa, mas sim a criação de tipos penais específicos e modernos para uma criminalidade que atinge contornos transnacionais. 


\section{CONCLUSÃO}

A reflexão sobre temática tão 'desconsiderada' pela massa social permeia discussões sobre princípios éticos do comportamento humano e nossa compreensão enquanto seres componentes de uma biodiversidade planetária, enquanto conhecemos a existência da vida somente no planeta Terra.

Embora constitua matéria que gera discussões infindáveis, Singer expressa, referenciando sobre o que denomina de tirania dos animais humanos sobre os nãohumanos, manifestando "[...] Esta tirania provocou e provoca ainda hoje dor e sofrimento só comparáveis àqueles resultantes de séculos de tirania dos humanos brancos sobre os humanos negros"(SINGER, 1975). Na continuidade ainda manifesta a dificuldade para discutir a liberdade e a opressão dos humanos sobre os não humanos e de como tal situação adquire contorno relevante: "A luta contra esta tirania é uma luta tão importante quanto qualquer outra das causas morais e sociais que foram defendidas em anos recentes".

$\mathrm{O}$ reconhecimento de direitos fundamentais a todas as espécies vivas é objeto em desenvolvimento para a espécie humana, o sentimento de pertença a um ente vivo maior, "Gaia", vagorosamente emerge nas relações da biodiversidade terrena. A "coisificação'" ${ }^{18}$ das demais espécies foi marca constante na história humana. Nesse sentido, a manifestação de Silva (2003, p. 68) identifica "Tradicionalmente o direito à vida não é um direito reconhecido a todos os seres vivos, nem mesmo a todos os animais, mas apenas aos seres humanos" e, realçando a excludente, manifesta em sequência: "Isto porque, enquanto a vida humana se vincula à ideia de dignidade, a vida nãohumana se atribui à ideia de preço".

No primeiro momento, buscamos a compreensão sobre os conceitos da biodiversidade e a necessária proteção da mesma para fins de sobrevivência da vida no planeta, sem deixarmos de considerar ser a espécie humana, embora a mais agressiva aos demais componentes da biosfera, uma das espécies mais frágeis para fins de dizimação. A compreensão que a biodiversidade é a garantia da sobrevivência dos próprios homens é o mecanismo de convencimento de todos para os fins de proteção. A vida na Terra não é somente a vida humana e o respeito, liberdade e dignidade devem ser mecanismos de preservação da vida e não somente do homem.

18 Assim referimos no sentido de especificar 'bens' apropriáveis e com atributos de propriedade que imperaram ao longo da história humana em relação aos demais seres vivos. 
Em um segundo instante, ao referenciarmos a Dignidade como componente de um direito fundamental, meta-humano, pois entendemos ser um direito fundamental de todos os seres vivos e não somente dos homens, buscamos a reflexão sobre aspectos aplicativos e não meramente conceituais. A mudança de paradigma na ciência e na consciência social demanda constante pensar. A transformação da informação em conhecimento e práxis decorrente não se perfectibiliza de forma instantânea, mas demanda estímulo reflexivo para sua efetivação.

Em um terceiro momento, buscando analisar a proteção da fauna por meio da legislação penal, identificamos inicialmente dados numéricos relativos ao crime de tráfico internacional de animais e sua posição frente aos crimes internacionais, ocupando posição variável entre $3^{\mathrm{a}}$ e $4^{\mathrm{a}}$ maior incidência criminal internacional, sendo superado de forma constante somente pelos crimes de tráfico de armas e tráfico de drogas, alternando na posição com o crime de tráfico de pessoas. Dentro do mesmo objetivo, analisamos o tipo penal balizador da punição para o delito de tráfico e o porquê de considerarmos 'pífio', ou seja,insuficiente para a proteção, passando a sugerir duas figuras típicas decorrentes, baseadas nos delitos de contrabando e descaminho que, a nosso ver, melhor absorvem os objetivos de proteção.

Os objetivos do presente estudo, identificados em seu preâmbulo serão plenamente atingidos através de sua compreensão e da discussão reflexiva, mesmo que subjetivamente, sobre os pressupostos enumerados, especialmente no que tange à consideração de que todos os seres vivos gozam de direitos fundamentais e que estes direitos, por nossa condição de 'seres inteligentes' devem receber a devida proteção. Não advogamos a mudança extrema no relacionamento com as demais espécies planetárias, cônscios dos ciclos da vida e das cadeias alimentares que constituem o equilíbrio da biosfera, mas defendemos sim que todas as espécies vivas do planeta, mesmo que destinadas à sobrevivência, tenham Dignidade inclusive em momentos de abate necessário.

A relação com as demais espécies vivas sofreu alterações substanciais. O apego aos animais domésticos ou domesticados e o reconhecimento da relevância das espécies como componentes de um extrato natural indissociável ao planeta cria a gênese de uma forma de compreensão distinta em relação ao objeto. Os não humanos detêm reconhecimento e afeto ímpares na história e a evolução da proteção deve reconhecer e respeitar tal aspecto. 
A reflexão não finda com este trabalho, contrário senso, buscamos lançar um pequeno elemento para fins do 'pensar moderno' e possibilitar com a abertura da temática que mais estudiosos igualmente exponham suas compreensões para o melhor desenvolvimento da ciência Direito.

\section{REFERÊNCIAS}

AILA - Associação Internacional de Animais: Tráfico de Animais Silvestres - A Magnitude do Problema.Disponível em: $<$ http://www.aila.org.br/maustratos/trafico-de-animais $>$.Acesso em:30 set.2017.

BOFF, Leonardo. Ética e Sustentabilidade. Caderno de Debates. Agenda 21. Ministério do Meio Ambiente. 2006.Disponível em: $<$ http://www.mma. gov.br/agenda21>. Acesso em: 13 out.2017.

BRASIL. Constituição da República Federativa do Brasil. Senado Federal. 1988.Disponível em:<http:/www.planalto.gov.br/ccivil_03/constituicao/ constituicao.htm>. Acesso em: 13 out.2017.

BRASIL. Decreto $n^{\circ} 76.623$, de 17.11.1975, aprova o Decreto Legislativo ${ }^{\circ}$ 54, de 1975, aprovou o texto da Convenção sobre o Comércio Internacional das Espécies da Flora e Fauna Selvagens em Perigo de Extinção (CITES), firmada em Washington, a 3 de março de 1973.Disponível em:<http:// www.planalto.gov.br/ccivil_03/decreto/antigos/d76623.htm>. Acesso em: 13 out.2017.

BRASIL. Câmara de Deputados. Relatório CPITRAFI.Disponível em: $<$ http://www.renctas.org.br/wp-content/uploads/2014/11/Rel_Fin_ CPI_Trafico_1.pdf>. Acesso em: 13 out.2017.

BRASIL. Lei de Crimes Ambientais, Lei $n^{\circ}$ 9.605/98. Congresso Nacional. 1998.Disponível em: <http://www.planalto.gov.br/ccivil_03/leis/L9605. htm>. Acesso em: 12 out. 2017.

BRASIL: RENCTAS - Rede Nacional de Combate ao Tráfico de Animais Silvestres: $1^{\circ}$ Relatório Nacional sobre o Comércio Ilegal de Fauna Silvestre.2014.Disponível em: $<$ http://www.renctas.org.br/wpcontent/uploads/2004/02/REL_RENCTAS_pt_final.pdf $>$. Acesso em: 12 out.2017. 
CANOTILHO, José Joaquim Gomes.Direito Constitucional e Teoria da Constituição. 3. ed. Coimbra. Portugal: Livraria Almedina, 2002.

CANOTILHO, José Joaquim Gomes.Estudo sobre direitos fundamentais. São Paulo: Editora Revista dos Tribunais. Coimbra. Portugal: Coimbra Editora, 2008.

CERVI, Jacson R.; CERVI, Taciana M Damo.O paradigma ecológico e a contribuição do direito para a superação da dicotomia meio ambiente e desenvolvimento.In:GIMENEZ, Charlise Paula Colet; LYRA, José Francisco da Costa (Org.).Diálogo e Entendimento - Direito e Multiculturalismo e políticas de cidadania e resoluções de conflitos. Tomo 7. Campinas: Millennium Editora, 2016.p. 71-90.

DEL'OLMO, Florisbal de Souza; MURARO, Mário Miguel da Rosa. Aproteção da dignidade da pessoa não humana: o habeas corpus do caso Cecilia.In:Revista Jurídica UniCuritiba, vol. 01, n . 46, Curitiba, 2017. p. 281-299, DOI: 10.6084/m9.figshare.5172403Disponívelem: $<$ http:// revista.unicuritiba.edu.br/index.php/RevJur/article/view/2009/1290>. Acesso em: 13 out.2017.

LEFORT, Claude. Pensando o político: ensaios sobre democracia, revolução e liberdade. Tradução Eliana M. Souza. Rio de Janeiro: Paz e Terra, 1991.

LEITE, José Rubens Morato; BELLO FILHO, Ney de Barros.Direito ambiental contemporâneo. Barueri: Editoras Manole, 2004.

LÉXICO. Dicionário de português online.Disponível em: <https://www. lexico.pt/exportar>.Acesso em: 30 set.2017.

MAURER, Béatrice. Notas sobre o respeito da dignidade da pessoa humana... ou pequena fuga incompleta em torno de um tema central. In: SARLET, Ingo Wolfgang (org.). Dimensões da Dignidade - Ensaios de Filosofia do Direito e Direito Constitucional. 2. ed. 2.tir. Porto Alegre: Livraria do Advogado Editora, 2013. p. 119-144.

MILARÉ, Édis: Direito do Ambiente. A gestão ambiental em foco. 5. ed. São Paulo: Revista dos Tribunais, 2007.

MILARÉ, Édis.Direito do ambiente: doutrina, jurisprudência, glossário. 5. 
ed. São Paulo: Revista dos Tribunais, 2007.

MORIN, Edgard; KERN, Anne Brigitte.Tierra Patria. Barcelona, Espanha: Kairós, 1993.

NUNES. Rizzatto. O princípio constitucional da dignidade da pessoa humana: doutrina e jurisprudência. São Paulo: Saraiva, 2002.

ORGANIZAÇÃO DAS NAÇÕES UNIDAS (ONU) - UNESCO. Declaração Universal dos Direitos dos Animais. Bruxelas - Bélgica, 27 de janeiro de 1978.Disponível em:<http://portal.cfmv.gov.br/portal/uploads/ direitos.pdf $>$. Acesso em: 28 set.2017.

ORGANIZAÇÃO DAS NAÇÕES UNIDAS (ONU): Objetivos do Desenvolvimento Sustentável (ODS). Disponível em: $<\mathrm{https}: / /$ nacoesunidas. org/pos2015>.Acesso em: 28 set.2017.

SILVA, Reinaldo Pereira e.Biodireito: a nova fronteira dos direitos humanos. São Paulo:LTr Editora, 2003.

SINGER, Peter: Ética no mundo real: 82 breves ensaios sobre coisas realmente importantes. Capítulo "Animais". Lisboa. Portugal: Edições 70 - Edições Almedina, 2017.p. 62-100.

SINGER, Peter.Libertação animal. Título original. Animal Liberation. 1975. Disponível em: $<$ https://olhequenao.files.wordpress.com/2011/12/ peter-singer-libertac3a7c3a3o-animal.pdf $>$. Acesso em: 13 out. 2017.

Recebido em: 16/10/2017. Artigo aceito em: 09/05/2018.

\section{Como citar este artigo (ABNT):}

DEL'OMO, Florisbal de Souza; MURARO, Mário Miguel da Rosa. O TRÁFICO INTERNACIONAL DE ANIMAIS E A PROTEÇÃO DA DIGNIDADE. Veredas do Direito, Belo Horizonte, v. 15, n. 31, p. 155177, jan./abr. 2018. Disponível em: $<$ http://www.domhelder.edu.br/revista/ index.php/veredas/article/view/1189>. Acesso em: dia mês. ano. 